\title{
IX. On the pollen of flowers
}

\section{Mrs. Agnes Ibbetson}

To cite this article: Mrs. Agnes Ibbetson (1822) IX. On the pollen of flowers, Philosophical Magazine Series 1, 60:291, 56-60, DOI: 10.1080/14786442208652787

To link to this article: http://dx.doi.org/10.1080/14786442208652787

$$
\text { 曲 Published online: } 29 \text { Jul } 2009 .
$$

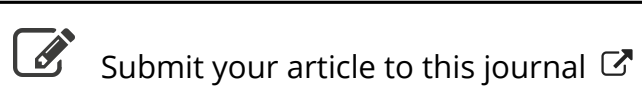

\footnotetext{
III Article views: 3
}

Q View related articles $₫$ 
IX. On the Pollen of Flowers. By Mrs. Agnes Ibeetson.

\section{To Dr. Tilloch.}

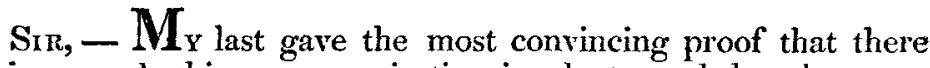
is no such thing as perspiration in plants, and that the water found under a glass when a vegetable is placed within it (without earth) is nothing more than the condensation of the atmosphere, shown and exemplified by the sky-light, and the water that runs on the stairs; and there being scarce a drop of moisture in the interior vessel when the plant is covered with two glasses, though the exterior cylinder is inundated as usual.

I now turn to my next subject, which will give the whole history of the pollen from the moment it is first protruded in the plant to the time it completes its fructification of the seed. The pollen is always formed in the tap root (Pl. I. fig. 1, $a a$ ): the anthers and filaments are a mere late production, and are never discovered in the plant till the bud forms them while completing other parts at the top of the plant: the pollen is therefore formed in the root perfectly uncovered (PI.I. fig. 1, a a a): if the tap root is eradicated, the pollen forms just above the cut; but is rarely in trees found in the side roots, except in firs. It passes up in all trees but in the Dioecious order, where, being separated entirely from the female, it runs up the pith or interior wood of the stem, in the male plant perfectly naked, fig. $11, n$. When the anthers begin to form in the male bud, in dioecious trees, nothing can be more evident than the entering of the pollen into them, fig. 2. They are then so stuffed and filled to bursting as to form a curious moving specimen for many minutes after being placed under the glass. It is then that the filaments are formed and shoot forth from the male bud, that they may carry the anthers and pollen into the air, where they generally swing for some hours, if not days. There is every reason to believe that they thus procure a quantity of gas, absorbing it by the help of their motion: thus they soon become ripe; and when the pistil has displayed those indications of being ready to complete the seed, by the swelling of the bubble of liquid at the summit, the pollen again leaves the anthers and flies to that nectarious drop, which attracts it to the pistil, and remains fastened by the hairs to which the balls adhere, and are in a short time dissolved by the juices of the pistil, down which it runs in various gutters till it has reached the seeds, which it enters mixed with the nectarious juice, and thus fructifies them.

When the pollen passes up in Dioecious trees, it forms a curious specimen: the balls of the pollen are generally large 
and run up the pith in different short vessels, figs. 1 and 2 . I know not a better example of Dioecious trees than the Willow: they are all the same in their flowering; two stamens alone appear out of the bud, from which they are classed, fig. 1.; the rest pass from the male bud to the female, and fructify all the seeds: fig. 4 is the nectary of the male bud of the Willow, fig. $3 \times$, of the female. It will be seen that the male is led up by the spiral wire, the female by the alburnum; and so invariable is this law, that it passes through every class of plants, and serves to distinguish the sexes in all the Cryptogamia plants, where such a mark is of consequence, and I never saw it vary in any one instance.

When the plants are Monoecious, and have the male and female in the same tree, you may always see, at the termination of the piece of stem, to which sex that piece belongs, and in herbaceous plants, such as the Indian Wheat, Carexes. 'The female first surrounds the male; they then cross each other, and the female is discovered fixed in the centre of the plant, to form the cone; in cutting the plant open all the way, the parts between the knots are always filled by the style of the female plant, while the seeds are growing under the knots: then the male flower passes by the female and makes its appearance at the top of the grass or corn.

It is most evident why the pollen comes from the tap root naked, or without anther or filament: a great quantity must pass up to the bud, and through the new shoot; the vessels are small, and would not contain either addition, especially the anthers, which are so formed with their four corners that they could not pass through a straight vessel, fig. 5 . I was a long time before I discovered this. It is curious not only to see the loads of pollen that run up the new shoot, but the early time they begin to run up. The stem, the moment the new shoot is beginning to protrude, and the pollen mounts it, is the first process for the new year, which in plants may be said to begin in August. I have often seen the pollen waiting in vast quantities near the new screw of the Poplar a month before the shoot was completed; then the moment they can rise and pass the screw, fig. 6 ; they are so loaded with the balls, so crowded together, that it is wonderful with what ease they pass up. It is admirable that every important part is formed in the root, and not one that is not absolutely essential, and of real consequence to the fructification:- the female flower-bud, for example, but not the leaf-bud; the pollen, but not the anthers and filament; the heart of the seed, but not the seed itself, which, large as it is, is a mere appendage and cover to the heart, which contains that shoot which is to form the next year's plant or tree.

Vol.60. No. 291. July 1822. 
The pollen, though it appears so small, is far from being so in Dioecions trees; and though they seem all like balls gathered in a heap, yet when examined by the microscope, they differ extremely in shape: some are round, some square, some triangular, some resemble a thick round cake; nor are they less various in colour, for though most of them are yellow, yet there are many white, purple, blue, and red; but most pollen belonging to the same genera have the same form and the same shape, which is an easy way of discovering the class of the flower. If the stamens are taken out, and the pollen is shaken on a dry glass, and a drop of water then allowed to fall near it, in a moment each ball of pollen (though before so apparently agglutinated) is scattered as if struek with electricity and flies to every part of the glass. They must contain much sulphureous matter, for they will often burn at the candle; but they do not melt in hot water, nor even in boiling spirit of wine, which will however sometimes draw from them a faint tint of colour; but it does not dissolve the poreer, though the pollen powder is directly melted by the nectarious juice on the pistil. Most probably it is resinous. They have invariably (let their shape differ ever so much) two separate parts; and two different liquids. The outward part (as at fig. 5) is formed of a slight cuticle, sometimes crossed, or with circular apertures, which show the dark parts within, and which often exhibit vessels shooting from the exterior ball, fig. $5 a a \times$, and. ejecting oil ; but when the inner ball bursts, it is discovered to be formed of a cartilaginous matter extremely strong; but all the apertures proceed from the upper surface alone and ejecting oil. But when the inner ball explodes, $a$ thin vapour pours from it like undulating smoke, fig. $6 \times$, and spotted with grains of black.

Rumphius and Hedwig, another German botanist, who had studied the subject as well as the microscopes then permitted, differed much : one of them said it was all oil, fig. 7 , which proceeded from the pollen ball. His antagonist insisted it was a gray liquid studded with black spots; they certainly were both right and both wong; since the mixture of the two opinions really composes the pollen ball, being oil without, and gray matter within. They are formed of such a beautiful matter, and the apertures are so contrived, as to throw a kind of luminous appearance within by means of a shining matter, which often produces a curious effect when contrasted with the black of the inner box: this adds not a little to those velvet flowers, such as the Heart-ease, \&c. The curious round ball of the Cucumber and Melon are so remarkable for their beauty, the outward figure is so light and highly fashioned, that it is difficult to describe it; see fig. 8, a a.

But 
But it is not anthers and pollen alone that form this necessary conjunction. 'The filament is of no little consequence: the thread which shoots from the anther after that is filled with pollen (thin as it is) must be perfectly hollow the whole way, fig. $9 a a$, and fig. 9 ; for so entirely does every ingredient, every nutriment, proceed from the root, that all must have free access to that part which apertains to it, and is intended to rise to its surface, - the upper part of the flower and the pistil. The anthers are and may be described as little bags of exquisite workmanship, each sack divided into two or four partitions, but always extremely filled by the pollen: when developed, the opening of these cases is most curiously managed with an art and cleverness nature alone can produce; since the more they are magnified the more beautiful they appear, which is never the case with the works of art. Sone of the anthers open at the end, fig. $9 c c$; some all the way down the side, fig. 9 bb. Some, still more extraordinary, are circular with a bar between each pollen ball, in order to ensure a passage thoroughly free through each part, when the filaments that serve as a foot-stalk to the anthers should possess a free communication. When the filaments that support them grow, they are formed perfectly hollow, that the dust may be changed should the moisture injure it. Sometimes the threads enlarge near the bottom to admit a nectary; at other times above. It is generally contrived with excessive art, as in the Antirhinum, where the stalk is twisted into a spiral before it joins the anther. 'This would appear to prevent the passage of the pollen; but I have exactly watched the flower; this spiral does not show itself till after the anther is completely stuffed with pollen: some anthers are formed like a divided heart, fig. $10 \mathrm{cc}$; some resemble a flower, $d d$. If communication were not necessary between the flower, and thus down to the root, there would have been no occasion for a cylinder reaching through the filament; whereas in the many thousands I have dissected I never found this part missing, and very often full of pollen: then the anthers have a hair peculiar to themselves which almost always conveys a coloured juice: progressive dissection soon proves these important truths, and unites them all, and gives a further insight into botanical nature, than years of more desultory studies on the same subject. Indeed it is the only way of becoming really acquainted with the interior of a tree.

To understand the stamen perfectly, there needs only to dissect a Dioecious tree or plant; there needs only to follow the picture the year round, as I have done, and see that pass within the tree, which is afterwards displayed without. In the Willow it is so entirely divided, the malc from the fomale, that it II 2 
is impossible to mistake them: the male Willow tree sends most of its pollen through the wood and pith by means of short vessels, which I have already shown: but it is very difficult to draw the pollen running within the anthers; though take a young flower of the male kind, and divide it, and it will be viewed directly. I hardly know a specimen plainer or more easily shown in the original, fig. 2. But there is one peculiarity which distinguishes the Dioecious; - the male plant is led up by the spiral wire, fig. 13, the female by the line of life, fig. $13 \times$ : this is so universally the case, that in all plants of this order, particularly the Cryptogamia, it is this that points out the male plant: I have dissected an immense number to trace the male and female flower, and invariably found this vessel, and the male is the more easily discovered from its always possessing so much motion; for in some plants it is absolutely violent, as in most of the Cryptogamia:-Dbut I shall give a letter on this subject. Your obliged servant,

AGNes Ibbetson.

\section{Description of the Plate.}

Fig. 1. Male flower of the Willow.

Fig. 2. Male flower of the Willow at an earlier stage, when the pollen are entering the anthers at a a a a.

Fig. $1 \times a a$. The tap root of the anther, with the first growth of the pollen.

Fig. 3, of the female flower of the Willow, with the heart of the seeds entering the seed-vessel.

Fig. 4. Pointing out the nectary in the male $d d d$, and the length of the nectary in the fenale flower.

Fig. 5. The exact interior shape of an oblong pollen, to show how the interior box is made, and how the exterior is formed to eject the oil.

Fig. $5 a a a \times$. A pollen ball: $\times$ the passage for the oil it ejects; and if some water swims on the glass it will be constantly seen to throw out a sort of pattern of oil.

Fig. 6. The sort of screw which stops the new shoot.

Fig. $6 x$. The ball of the Melon or Gourd, with the interior manner of ejecting the gray matter.

Fig. 7. Pollen ball.

Fig. $8 a a$. Triangular ball with the oil vessels $a a$ completed.

Fig. 9. The filaments: fig. 9 a a a, to show they are hollow.

Fig. 9.f. The filaments.

Fig. $10 \mathrm{cr}$. Double heart.

Fig. 11, Sicm, with the pollen fassing up. 


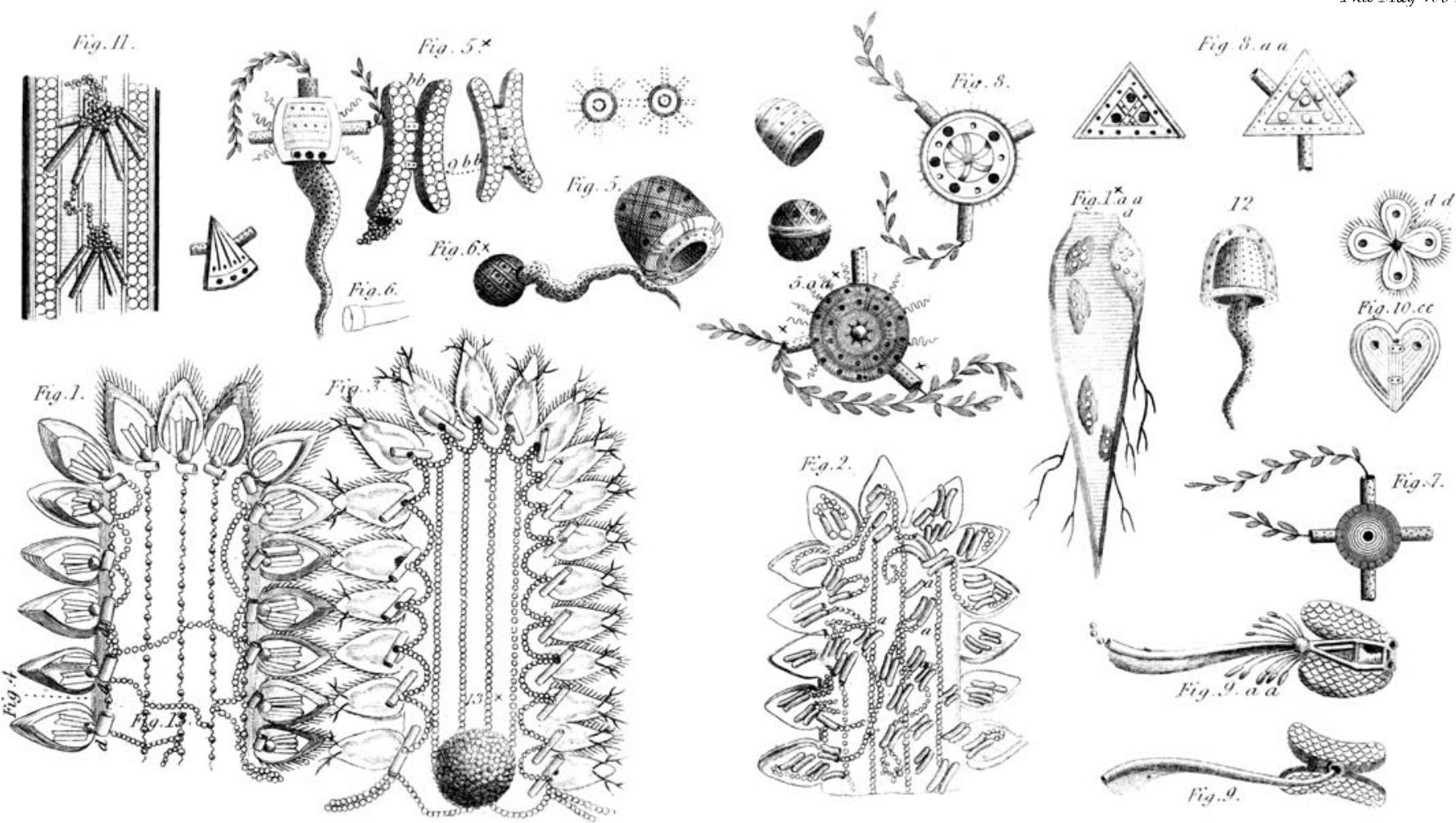

